$$
\text { 흥인지문의 진동특성 및 상반성 분석 }
$$

\title{
Investigation on Vibration Characteristics and Structural Reciprocity of Heunginjimun
}

\author{
최 재 성†.이 성 경*. 민 경 원**.윤 원 규***. 김 덕 문**** \\ Jae-Sung Choi, Sung-Kyung Lee, Kyung-Won Min, Weon-Kyu Yoon \\ and Derk-Moon Kim
}

(2009년 11월 9일 접수 ; 2010년 3월 19일 심사완료)

Key Words : Heunginjimun(흥인지문), Ambient Vibration Test(상시진동 실험), Impact Test(충격 실험), Wooden Structure(목구조), Architectural Heritage(건축 문화재), Linearity(선형성), Time Invariance (시불변성), Reciprocity Principle(Maxwell의 상반정리)

\begin{abstract}
Heunginjimun designated as a Treasure No.1 is a two-story wooden structure with 5 bay and 2 bay in its front and side views, respectively. This paper presents an investigation on vibration characteristics of Heunginjimun through both ambient vibration and impact hammer tests. Ambient vibration test was performed to identify the natural frequency of Heunginjimun from the spectrum analysis of time history. Impact hammer test was undertaken to find the frequency of Heunginjimun which is affected by the surrounding traffics and to verify the reciprocal principle for the wooden structural system. Ambient vibration test results of Heunginjimun showed that the natural frequencies in two principal axes $1.5 \mathrm{~Hz}$ and $1.1 \mathrm{~Hz}$, respectively. It was confirmed from impact hammer tests for a ground that the frequency of $4.2 \mathrm{~Hz}$ is caused by the traffics surrounding Heunginjimun. It was also observed that from the impact hammer test results between two locations in Heunginjimun that the transfer functions measured from two corresponding locations coincided well with each other. This result shows that the wooden structural system is globally linear, and the reciprocal principle is established.
\end{abstract}

\section{기 호 설 명}

\section{$\gamma^{2}:$ 상관계수}

$S_{x x}, S_{y y}$ : Autopower spectrum

† 교신저자; 정회원, 단국대학교 건축대학 건축공학과, (주)누벨 비 에이엔씨

E-mail : phdr007@naver.com

Tel : (02)978-9850, Fax : (02)978-9852

* 정회원, (주)비코시스템

** 정회원, 단국대학교 건축대학 건축공학과

*** (주)누벨 비 에이엔씨

****국립문화재연구소

$$
\begin{aligned}
& S_{x y}: \text { Cosspower spectrum } \\
& \mathrm{x} \quad: \text { 입력신호 } \\
& \mathrm{y}: \text { 출력신호 }
\end{aligned}
$$

\section{1. 서 론}

서울 성곽은 조선시대 중요한 국가시설이 있는 한성부를 보호하기 위해 만든 도성(都城)으로, 흥인 지문은 성곽 8 개의 문 가운데 동쪽에 있는 문이다. 흔히, 동대문이라고도 하는 흥인지문은 조선 태조 7 년(1398)에 완성하였다가 단종 원년(1453)에 개축 
하였고, 현재의 흥인지문은 고종 6년(1869)에 새로 지은 것이다. 흥인지문은 앞면 5 칸, 옆면 2칸 규모 의 2 층 건물로, 지붕은 앞면에서 볼 때 사다리꼴모 양을 한 우진각 지붕이다. 지붕 처마를 받치기 위해 장식하여 만든 공포가 기둥 위뿐만 아니라 기둥 사 이에도 있는 다포 양식으로, 그 형태가 가늘고 약하 며 지나치게 장식한 부분이 많아 조선 후기의 건축 양식을 잘 나타내주고 있다. 또한 바깥쪽으로는 성 문의 수비와 방어를 효과적으로 수행하기 위하여 반원 모양의 옹성(甕城)을 축조하여, 도성의 8 개 성 문 중 유일하게 옹성을 갖추고 있으며, 1963년 1월 21 일에 보물 제 1 호로 지정되었다 ${ }^{(1)}$.

흥인지문을 둘러싸고 있는 도로에는 한 노선에 하 루 십만대가 넘는 차량이 통행하여, 도로 사정에 비 해 혼잡한 교통량을 나타내고 있으며 차량매연에 의 한 대기환경의 오염도 심하다. 지하에는 흥인지문 우 측을 통과하는 1 호선이, 배면으로 4 호선 환승역이 위 치하고 있어 두 노선을 합쳐 하루 천회이상 지하철이 운행되고 있다. 흥인지문을 중심으로 반경 $200 \mathrm{~m}$ 내에 는 재래시장과 저층의 상가건물이 줄지어 있고, 반경 200 550 m 내에는 최대 34층 규모의 두산타워를 비 롯한 현대식 고층 쇼핑몰이 빌딩군을 형성하고 있어 교통 혼잡을 더욱 가중시키고 있다. 문화재의 유지관 리 차원에서 이러한 주변 차량 및 지하철에 의한 흥 인지문의 진동영향을 평가하는 것이 필요하다.

현재 국내 문화재의 진동 영향을 평가를 위한 평 가기준은 마련되어 있지 않기 때문에, 외국의 진동에 민감한 구조물 또는 문화재 등에 대한 기준 등을 평 가 및 관리기준으로 활용하고 있는 상황이다 (2). 그러 나, 이러한 기준들이 우리 문화재에도 적합한가에 대한 깊이 있는 연구가 진행된 사례는 없었다. 따라 서, 문화재 보존을 위한 진동의 합리적 기준 마련이 라는 과제에 앞서서 우리 문화재의 동적 거동특성 을 파악하는 연구가 먼저 선행되어야 한다.

우리나라의 전통목조건물의 접합부는 기둥과 초 석의 접합부, 공포 부분의 접합부, 부재간 접합부 등 크게 3 가지로 나누어 볼 수 있다. 이러한 접합 부는 강접합 또는 핀접합의 형태가 아닌 부재 접촉 면이 단순히 맞대어 있어 해당 면에서 발생되는 압 축력과 마찰력이 접합 관계를 유지시켜 주는 구조 형식이다. 이러한 요소들의 해석을 위한 모형화 방 법은 여러 문제점들이 있으며 그 해결방안으로 스
프링 요소 등으로 모형화하는 방안들이 연구 및 적 용되어지고 있다 ${ }^{(3-4)}$.

이 논문에서는 여러 중요 문화재들 중에서 흥인지 문 중에서 하부의 육축을 제외하고, 2 층 구조의 목구 조인 문루를 실험 대상으로 선정하여 상시진동 측정 법 및 충격 가진법을 이용하여 진동을 측정 및 분석 하여 상호비교하였다. 여기서, 문루(門樓, the upper story of a castle gate)는 궁문, 성문, 지방관청의 바 깥문 등의 위에 지은 건물을 의미하며, 성문을 축조 하기 위하여 무사석 등 큰 돌로 축조한 성벽을 육축 (陸築, the wall for a castle gate)이라 한다 ${ }^{(1)}$. 그리고 선형이론에 근거한 Maxwell의 상반성(5) 등의 성질 을 실험적으로 검증하는 것을 목적으로 한다. 이는 목조 건축물의 선형화를 통해 동특성을 찾고 단순 화된 해석모델을 구축하기 위해 우선적으로 확인할 필요가 있다.

\section{2. 연구 방법}

\section{1 측정방법 개요}

기존 건축물의 동적특성을 파악하는 실험방법 중 에서 상시진동측정에 의한 방법은 다른 방식에 비 해 다음과 같은 특징을 갖고 있다. 건축물을 가진하 는 힘을 외부의 미동에 의한 것으로 가진장치를 준 비할 필요가 없기 때문에 비용면에서 매우 우수한 방법이다. 미동의 진동원으로는 바람, 파랑, 지반의 맥동 등의 자연적인 것과 철도, 자동차 등의 교통진 동, 혹은 공장과 공사 등에 의한 지반진동 등의 인 공적인 것이 있다 ${ }^{(6)}$.

모드 해석에 사용되는 가장 널리 알려진 가진 방 법은 충격 또는 햄머 가진이다. 충격에 의해 발생되 는 파형은 짧은 시간의 과도적인 에너지(transient energy) 전달이다. 스펙트럼은 $0 \mathrm{~Hz}$ 에서 최대 진폭을 갖고 주파수가 증가함에 따라 진폭이 감쇠하는 연속 적인 신호이다. 충격햄머(impact hammer)는 단지 몇 그램에서부터 수천 톤에 이르기까지 다양하게 만들 수 있으며 작은 것은 $0 \sim 5,000 \mathrm{~Hz}$ 까지의 주파수를 가진시킬 수 있고, 가장 큰 것은 $0 \sim 10 \mathrm{~Hz}$ 사이의 주파수를 가진시킬 수 있다(7).

\section{2 측정방법 개요}

흥인지문의 진동측정시 가속도센서는 미세진동의 
측정이 가능한 Seismic ICP Type의 393B05, 충격 햄머는 ICP Type의 086D50을 사용하였으며, 휴대

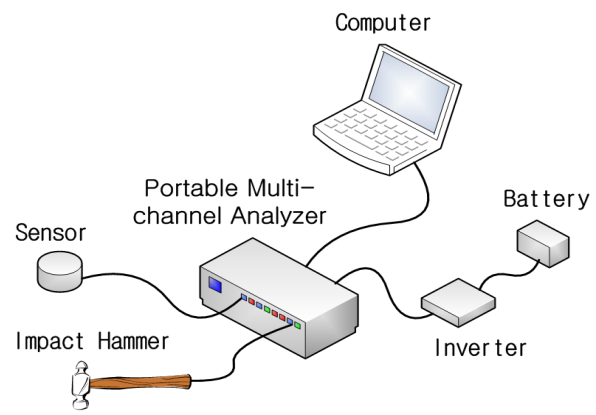

Fig. 1 The testing system

Table 1 Performance of sensors

\begin{tabular}{c|c}
\hline \hline Items & Contents \\
\hline Type & Seismic ICP accelerometer \\
\hline Sensitivity & $1.02 \mathrm{~V} /\left(\mathrm{m} / \mathrm{s}^{2}\right)$ \\
\hline Frequency range & 0.2 to $1700 \mathrm{~Hz}$ \\
\hline Broadband resolution & $0.00004 \mathrm{~m} / \mathrm{s}^{2} \mathrm{rms}$ \\
\hline
\end{tabular}

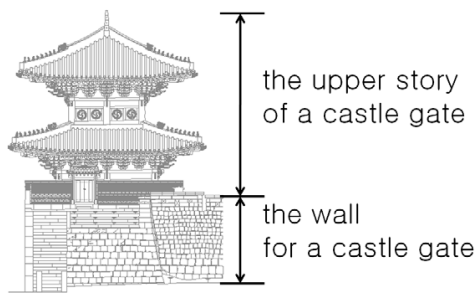

(a) Specification

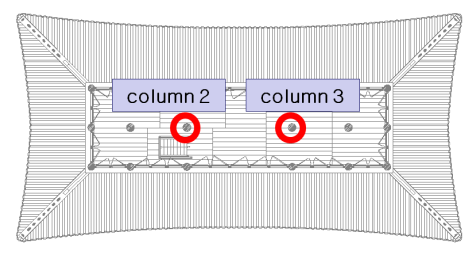

(b) Roof plan
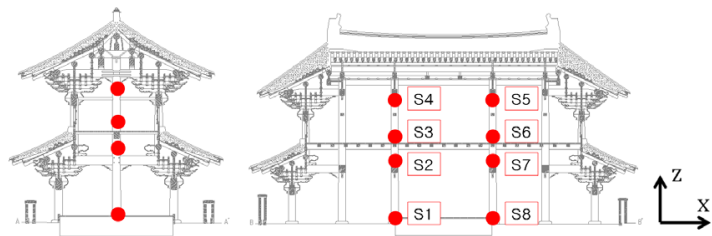

(c) Lateral section

(d) Longitudinal section

Fig. 2 Measuring locations
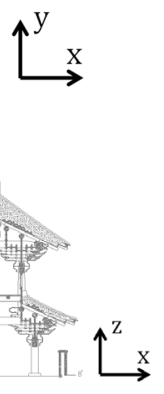

용 다채널 분석기는 PIMENTO P103을 사용하였 다. 분석 프로그램은 PIMENTO S/W Rev 6.1 및 Test.Xpress S/W Rev 3A 등을 사용하였다. 각 장 비들의 배열은 Fig. 1 과 같으며, 측정데이터의 노이 즈에 대한 영향을 최소화하기 위해 배터리를 사용 하여 전원을 공급하였다. Table 1은 실험에 사용된 가속도센서의 성능을 정리한 것이다.

\section{3 측정 위치 및 방법}

사용된 가속도센서는 총 8 개이며, Fig. 2 와 같이 흥인지문의 전체적인 구조적 거동이 나타날 것으로 예상되는 중앙부 2 개의 기둥에 $\mathrm{x}, \mathrm{y}$ 방향으로 각각 8 개소에 설치하였다. 센서의 고정 방식은 부재 표면 에 철편(와셔 등)을 부착한 후에 자석 마운트를 센 서 하단에 부착하여 관심 주파수 대역에서 기둥과 센서가 일체로 거동하도록 고정하였다.

상시진동 측정 시에는 동일방향으로 설치된 8 개 소의 센서를 동시에 사용하여 측정하였다. 측정횟수 는 5 회 이상 측정하였다. 측정 데이터의 분석은 Table 2 와 같은 설정에 의해 충분히 긴 시간동안 측정된 데이터를 중첩(overlap)이 되지 않도록 일정

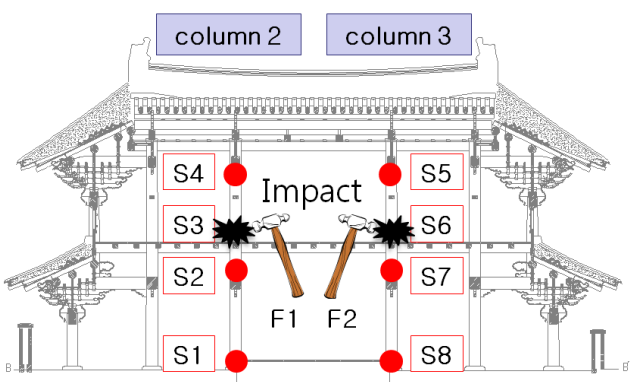

Fig. 3 Impact testing at columns 
구간으로 분활하여 주파수 분석을 수행하였다. 이 경우 각 데이터 별로 7 개의 앙상블이 생기며, 각 앙상블에 hanning window를 적용하여 누설오차 발 생을 방지하였다. 각 앙상블의 주파수 분석은 위상 의 왜곡이 생기지 않도록 식 (1), (2)와 같이 autopower spectrum을 구한 후에 다시 autopower spectrum의 제곱근을 구하는 방법으로 그 크기를 구했다. 이러한 개별 데이터에서 구해진 개별 앙상 블의 주파수 분석 결과는 식 (3)과 같이 선형평균 (linear average)을 하여 평균화된 앙상블을 구하였 으며, 개별 데이터의 평균화된 앙상블 결과들을 다 시 선형평균하였다.

$$
S_{y y}=B(\omega) \cdot B^{*}(\omega)
$$

$$
\text { Amplitude of FFTs }=\sqrt{S_{y y}(\omega)}
$$

여기서, $B(\omega)$ 은 출력의 시간영역 신호 $y(t)$ 의 푸리 에 변환을, *은 켤레복소수를 의미하며, $S_{y y}(\omega)$ 는 출력의 autopower spectrum이다.

$$
\bar{S}=\frac{1}{n} \sum_{i=1}^{n} S_{i}(\omega)
$$

여기서, $S_{i}(\omega)$ 는 $i$ 번째 앙상블의 주파수 분석 결과 의 크기값이며, $n$ 은 해당 데이터에서의 앙상블 개 수이다.

충격가진 진동 측정 시에는 상시진동법으로 진동 측정하였을 때와 동일한 7 개 위치에 설치되어 있는 센서에서 진동을 동시 측정하고, 충격햄머로 임의의 센서 위치 1 개소 또는 측정 대상 기둥의 인접 지면 $(125 \mathrm{~mm}$ 이격 위치)을 가진하는 방법으로 측정하였 다. 측정횟수는 5 7회 이상 측정하였다.

충격가진법의 데이터의 분석은 Table 2 와 같이, 가

Table 2 Settings for frequency analysis

\begin{tabular}{c|c|c}
\hline \hline Items & $\begin{array}{c}\text { Ambient } \\
\text { vibration test }\end{array}$ & Impact test \\
\hline Record time & $5 \mathrm{~min}$. & $1 \mathrm{~min}$. \\
\hline Block time & $40.96 \mathrm{~s}$ & $3.2678 \mathrm{~s}$ \\
\hline Block size & 8,192 & 32,768 \\
\hline Freq. resolution $(\Delta \mathrm{f})$ & $0.024 \mathrm{~Hz}$ & $0.305 \mathrm{~Hz}$ \\
\hline Window & Hanning & $\begin{array}{c}\text { Force / } \\
\text { Exponential }\end{array}$ \\
\hline
\end{tabular}

진력 신호에는 force window를, 응답 신호에는 exponential wondow를 적용하여 스펙트럼 누설오차 발생 방지하였다 ${ }^{(8)}$. 또한, 결과 분석은 식(4) (6)과 같이 H1 함수를 이용하여, 주변 교통진동 신호의 유 입에 따른 출력신호(가속도 신호)의 노이즈를 보상한 $\mathrm{FRF}$ 를 계산하였으며 결과의 유의성을 확인하기 위 하여 식(7)과 같은 상관계수(coherence) $\gamma^{2}$ 도 계산 하여 비교 분석하였다. 이때 충격진동 신호는 과도 신호이므로 유효한 데이터 개수만큼 산술 평균한 값을 사용하였다(9).

$$
\begin{aligned}
& S_{x x}=A(\omega) \cdot A^{*}(\omega) \\
& S_{x y}=A(\omega) \cdot B^{*}(\omega) \\
& F R F=H_{1}=\frac{S_{x y}(\omega)}{S_{x x}(\omega)}
\end{aligned}
$$

여기서, $A(\omega), B(\omega)$ 은 각각 입력 및 출력의 시간 영역 신호 $x(t), y(t)$ 의 푸리에 변환을, *은 켤레복 소수를 의미하며, $S_{x x}(\omega)$ 는 입력의 autopower spectrum이며, $S_{x y}(\omega)$ 는 입력과 출력의 cosspower spectrum이다.

$$
\gamma^{2}=\frac{\left|S_{x y}^{2}(\omega)\right|}{S_{x x}(\omega) S_{y y}(\omega)}
$$

\subsection{Maxwell의 상반정리(reciprocity principle)}

실험적 모달해석을 수행하기 위해서는 5 단계의 과정이 수행되어야 한다. 1단계는 실험장비 및 대상 물의 셋팅, 2 단계는 데이터의 획득, 3 단계는 시스템 식별, 4 단계는 결과의 검증, 5 단계는 체계적 방법으 로 시스템의 개선을 위한 정보획득 등이다(5). 이 논 문에서는 3 5단계로 연구를 진행하기 위한 1단계 와 2 단계에 대한 실험내용 및 분석을 기술하였다.

모달해석 이론에서의 기본적인 가정은 선형성 (linearity), 시불변성(time invariance), 관측성(observability), Maxwell의 상반정리(reciprocity principle) 등이 있다 ${ }^{(5)}$. 이 논문에서는 접합부의 비선형적 특 성이 지배적인 목구조물에 대해서 전체 구조물을 선형으로 가정한 후에 진동측정법을 이용한 다양한 해석기법을 위한 기본적인 확인 작업으로서 이러한 가정의 만족여부를 검증하였다. 
가역정리 또는 상반정리는 두 개의 물리량을 관 련시키는 계수가 대칭성을 갖는다는 물리적 정리로 써, 식 (8)과 같이 $\mathrm{A}$ 점에 외력 $\mathrm{F}$ 를 가해서 $\mathrm{B}$ 점에 응답 $\mathrm{X}$ 가 생기는 경우, 반대로 $\mathrm{B}$ 점에 외력 $\mathrm{F}$ 를 가 하면 $\mathrm{A}$ 점에 응답 $\mathrm{X}$ 가 생기는 관계를 의미한다. 이 정리는 충격가진법에도 적용되며, 이 논문에서는 측 정의 편리성을 고려하여 Figs. 3, 4와 같이 햄머를 이동시키는 방법으로 현장실험을 수행하였다.

$$
F R F=\frac{X_{B}}{F_{A}}=\frac{X_{A}}{F_{B}}
$$

여기서, $F_{A}$ 와 $F_{B}$ 는 각각 $\mathrm{A}$ 와 $\mathrm{B}$ 점에 가하는 충격 하중이며, $X_{A}$ 와 $X_{B}$ 는 각각의 측정응답이다.

\section{3. 실험 결과 및 분석}

\section{1 상시진동 측정법에 의한 결과 분석}

Fig. 5와 Fig. 6은 상시진동측정 자료를 이용하여

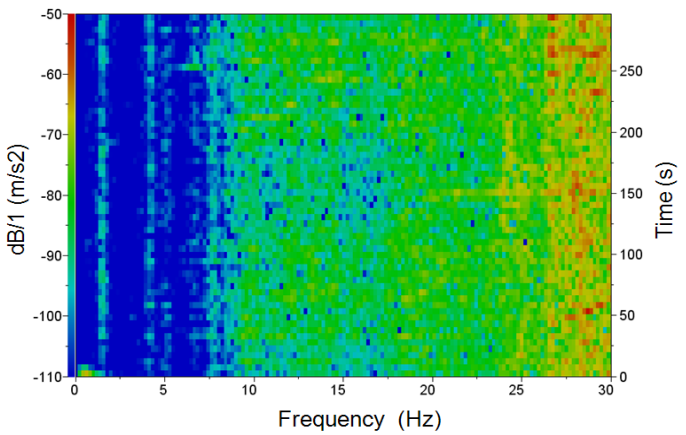

Fig. 5 Frequency-time plot by ambient vibration(x direction at S4)

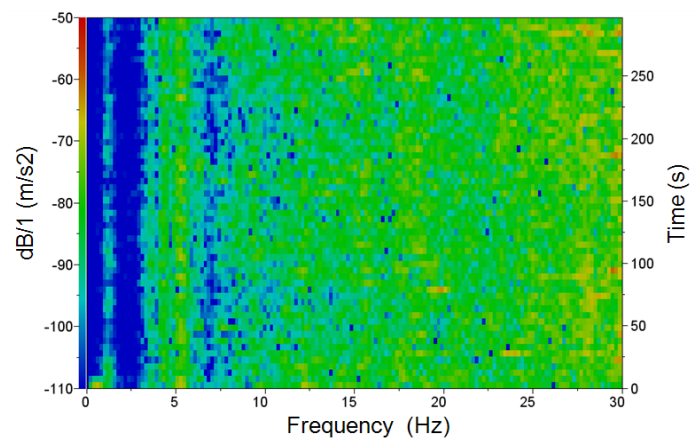

Fig. 6 Frequency-time plot by ambient vibration(y direction at S4)
시간 변동에 따른 주파수분석 결과의 변화 경향을 분석한 그래프이다. 각 방향별 결과를 살펴보면, $\mathrm{x}$ 방향의 $1.5 \mathrm{~Hz}, \mathrm{y}$ 방향의 $1.1 \mathrm{~Hz}$ 를 비롯하여 약 $8 \mathrm{~Hz}$ 이하의 구간에서 시간 변화와 상관없이 일정한 직 선이 나타나고 있으며, 이러한 시불변하는 직선이 나타나는 주파수들은 흥인지문 상부 문루의 각 방 향별 고유진동수이거나 외부의 지속적인 강제진동 수 성분이다.

Fig. 7은 상시진동측정법에 의한 측정결과에 대한 주파수분석 결과를 $\mathrm{x}, \mathrm{y}$ 방향별로 정리한 것이다. Fig. 5와 Fig. 6에서와 동일하게 x방향에 있어서는 $1.5 \mathrm{~Hz}$ 등, $\mathrm{y}$ 방향에 있어서는 $1.1 \mathrm{~Hz}$ 등에서 지배적 인 피크 성분이 나타났다. 또한, 측정위치 ' $\mathrm{S} 1$ ', ' $\mathrm{S} 2$ ', ' $\mathrm{S} 3$ ' 및 ' $\mathrm{S} 4$ '에서 측정한 결과가 각각 대칭위 치인 'S8', 'S7', 'S6' 및 ' $\mathrm{S} 5$ '에서 측정한 결과와 일치하고 있다. 따라서 2 개의 기둥에서 동일 진동수 로 일체적인 거동을 하고 있음을 확인할 수 있다.

그리고 Fig. 7에서 $4.2 \mathrm{~Hz}$ 성분의 피크는 $\mathrm{x}, \mathrm{y}$ 방향 에서 동시에 나타나고 있어서 대상구조물이 해당 진 동수에서 비틀림 모드로 거동하는 것으로 추정된다.

\section{2 충격가진 측정법에 의한 결과 분석}

Fig. 8(a),(b)와 Fig. 9(a),(b)는 문루 2층 기둥의 2 개소를 각각 타격하였을 때(Fig. 3 참조)의 가진력과 가속도 응답과의 FRF 결과를, Fig. 8(c),(d)와 Fig. $9(\mathrm{c}),(\mathrm{d})$ 는 coherence $\left(\gamma^{2}\right)$ 를 도시한 것이다.

Fig. 8(a),(b)와 Fig. 9(a),(b)의 피크에 표기된 진동 수에서의 coherence값을 Fig. 8(c),(d)와 Fig. 9(c),(d) 에서 살펴보면, 해당 진동수에서의 $\gamma^{2}$ 값은 0.8 이 상의 값을 나타내고 있으며, 이로서 해당 진동수가 고유진동수로 간주될 수 있다 ${ }^{(10)}$.

Fig. 8(c),(d)와 Fig. 9(c),(d)을 살펴보면 x방향은 약 $6 \mathrm{~Hz}$ 이하 구간에서, $\mathrm{y}$ 방향은 약 $3 \mathrm{~Hz}$ 이하 구 간에서 coherence값 $\left(\gamma^{2}\right)$ 이 전체적으로 많이 떨어지 는 현상이 나타나고 있다. 이는 해당 고유진동수에 서 공진 현상을 발생시키기에 가진력의 크기가 충 분하지 못했거나, 충격가진 측정법의 가진 위치가 해당 고유진동수에서 변위가 0 인 지점(node point) 이거나 그 지점과 가까울 때 주로 나타나는 현상이 다 ${ }^{(7)}$. 가진력의 크기는 측정대상물이 보물 1 호의 문 화재임을 감안할 때 파손의 위험 때문에 충분히 크 게 할 수 없었다. 따라서 이러한 문제는 다양한 위 

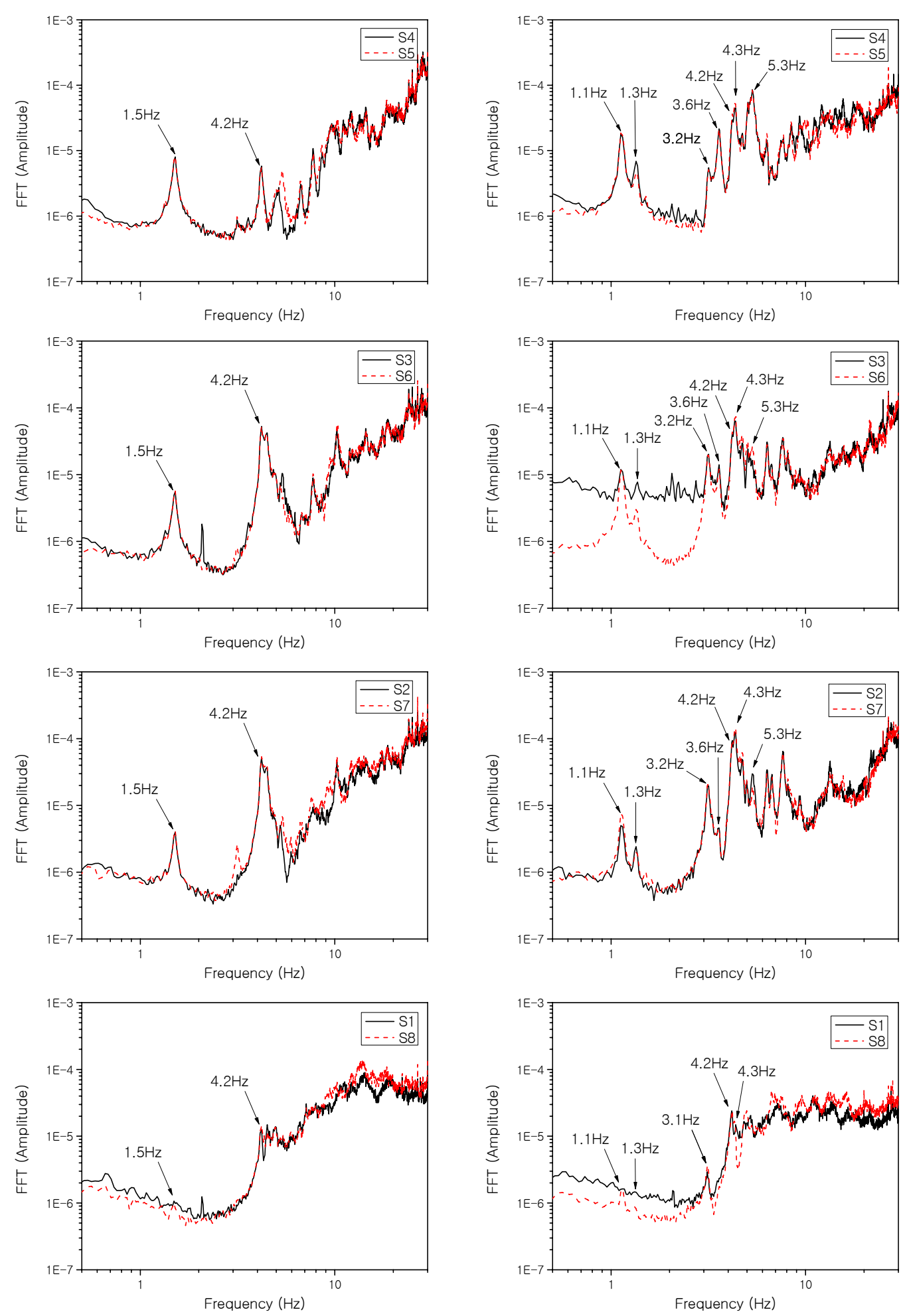

(a) $\mathrm{x}$ direction

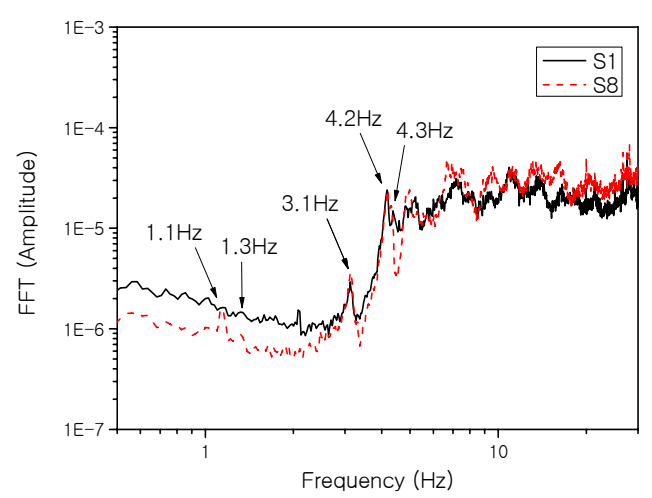

(b) y direction

Fig. 7 Ambient vibration test results 


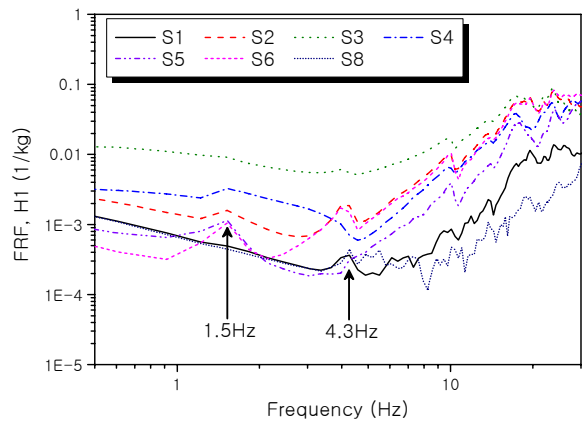

(a) FRF(impacting case, F1)

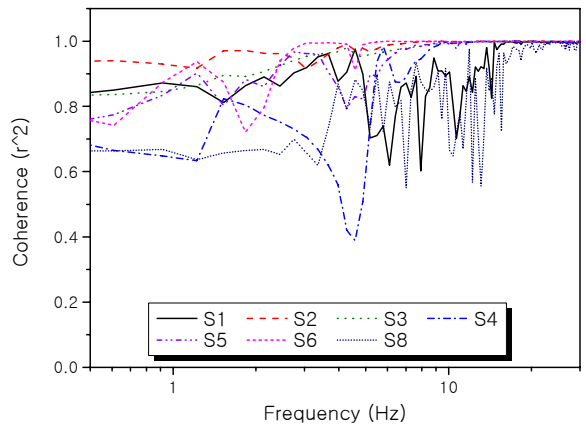

(c) Coherence(impacting case, F1)

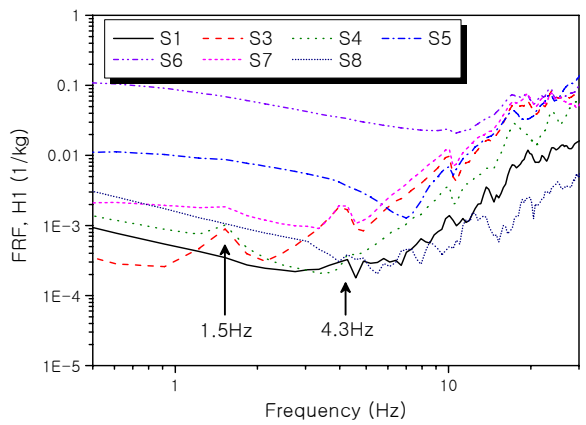

(b) FRF(impacting case, F2)

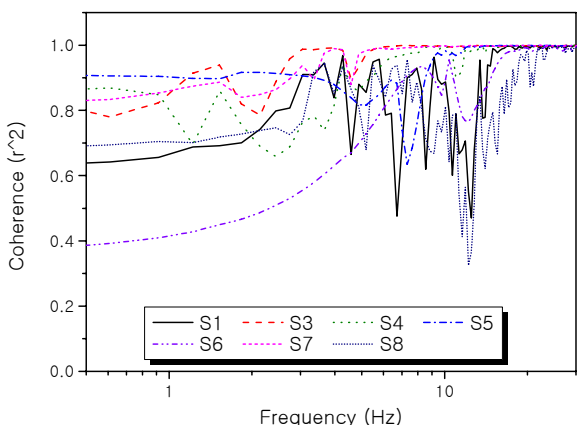

(d) Coherence(impacting case, F2)

Fig. 8 Impact hammer test results(x direction)

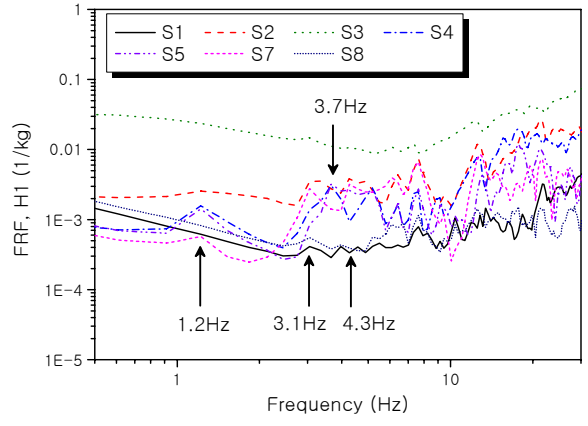

(a) FRF(impacting case, F1)

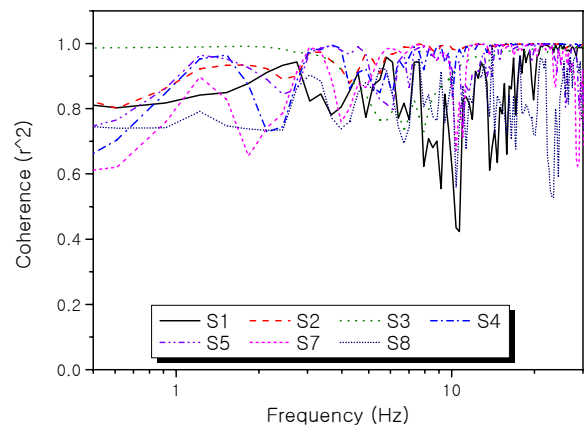

(c) Coherence(impacting case, F1)

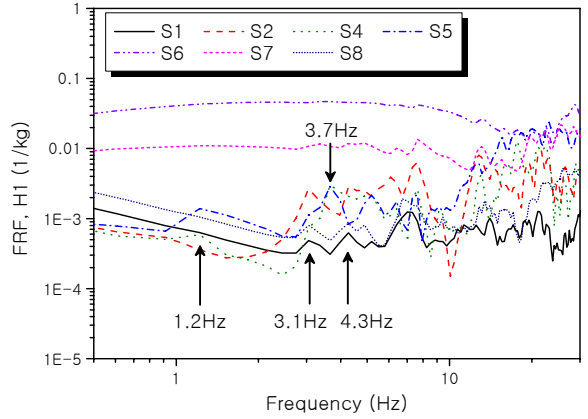

(b) FRF(impacting case, F2)

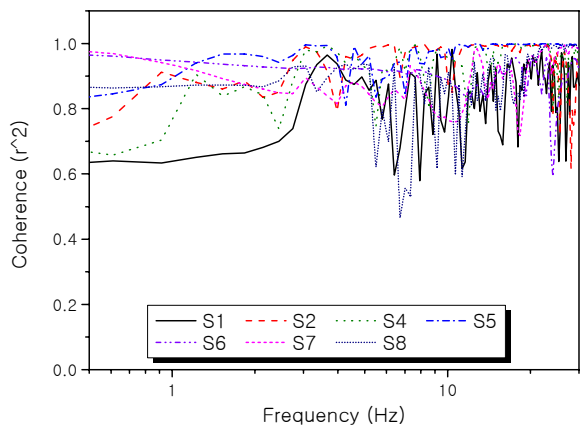

(d) Coherence(impacting case, F2)

Fig. 9 Inpact hammer test results(y direction) 


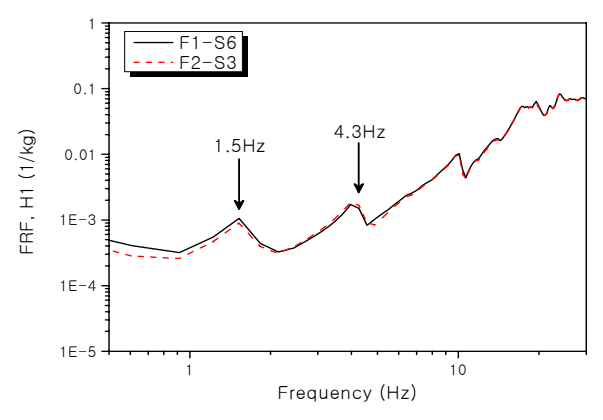

(a) F1 and F2(impact at columns)

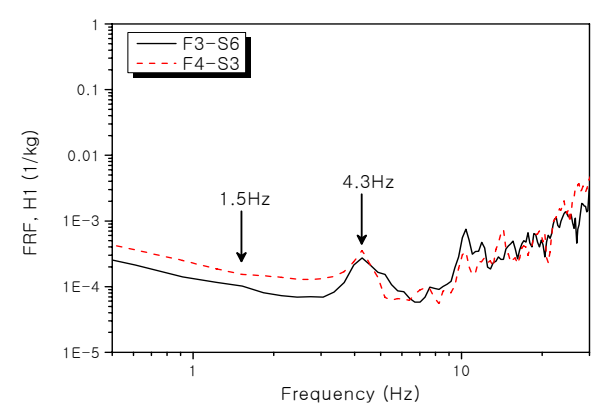

(b) F3 and F4(impact at bases)

Fig. 10 Two-point Impact hammer test results(x direction)

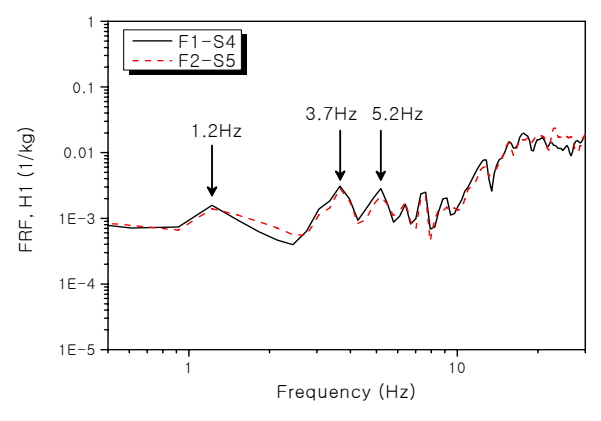

(a) F1 and F2(impact at columns)

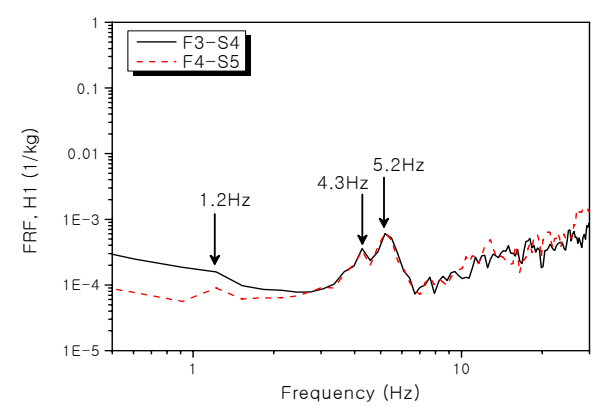

(b) F3 and F4(impact at bases)

Fig. 11 Two-point impact hammer test results(y direction)

치에서 가진하거나 응답을 측정하여 작은 충격력으 로도 충분한 가진력이 전달될 수 있는 최적의 가진 위치 또는 응답측정 위치를 찾음으로서 해결될 수 있을 것으로 판단된다. 그리고 이러한 문제는 추후 연구과정에서 보완되어야 할 것이다.

Fig. 8(a),(b)와 Fig. 9(a),(b)에 의하면, x방향에서 는 $1.5 \mathrm{~Hz}, 4.3 \mathrm{~Hz}$ 및 여러 고유진동수 피크가, $\mathrm{y}$ 방 향에서도 $1.2 \mathrm{~Hz}, 3.1 \mathrm{~Hz}$ 및 여러 고유진동수 피크가 나타났다. 상시진동측정법의 Fig. 7과 비교하였을 때, 거의 일치하는 진동수 값을 나타내고 있으며, 해당 오차는 Table 2의 $\Delta f$ 의 차이에 의한 오차로 판단 된다.

Fig. 10(b), Fig. 11(b)는 문루 1층에서 기둥 인접 의 지면 2 개소(육축 상부)를 각각 타격하였을 때 (Fig. 4 참조)의 방향별 $\mathrm{FRF}$ 결과를 도시한 것이다. $\mathrm{x}$ 방향에서는 $4.3 \mathrm{~Hz}$ 에서, $\mathrm{y}$ 방향에서는 $1.2 \mathrm{~Hz}, 5.2$ $\mathrm{Hz}$ 에서 고유진동수 피크가 나타났다. $\mathrm{x}$ 방향의 1.5 $\mathrm{Hz}$ 에서도 미세하게 피크가 나타나고 있는데 이는 구조물을 직접적으로 가진하지 않고 인접 지면을
가진하다 보니 전달된 가진력의 크기가 해당 주파 수에서 충분히 전달되지 않아서 나타난 현상으로 판단된다.

\section{3 상반 관계 분석}

Fig. 10과 Fig. 11은 Fig. 3, Fig. 4와 같이 기둥 및 바닥면에 각각 2 개소를 선정하여 측정된 데이터의 $\mathrm{FRF}$ 결과가 식 (8)과 같은 상반성을 만족하는 것을 확인하기 위하여 상호 비교한 것이다. Fig. 10(a)과 Fig. 11(a)는 기둥을 가진하였을 때의 결과로서, 'S3'을 타격했을 때(F1) 'S6'의 응답을 이와 반대의 경우(F2)와 비교한 것이다. Fig. 10(b)과 Fig. 11(b) 는 육축 상부 지면을 타격했을 때를 비교한 것이다.

기둥 가진시, 가진 위치 및 가진력의 크기가 다 름에도 불구하고 $\mathrm{FRF}$ 에서의 고유진동수 및 크기가 일치하였다. 또한 지면 가진시에도 지면 즉 흥인지 문의 육축과 문루의 연성 효과가 기둥별로 차이가 있을 수 있음을 감안 할 때, 대체적으로 일치하는 결과를 나타내었다. 
이와 같이, 이 실험의 가진력의 크기 범위 내에 서는 구조물이 선형적으로 거동을 하며, Maxwell의 상반정리를 만족함을 알 수 있다.

\section{4. 결 론}

시간변화에 따른 주파수분석 그래프에서 시불변 적으로 나타나는 진동수 성분을 파악한 후에, 앙상 블들의 평균화된 주파수분석 결과에서 해당 피크들 의 진동수 값을 확인하였다. 그리고 충격가진 실험 법에 의해 해당 진동수가 방향별 고유진동수임을 확인하였다. 참고문헌들 ${ }^{(11 ~ 13)}$ 에 따르면 도로교통 및 지하철에 의한 지반 전달 진동이 대체적으로 $4 \mathrm{~Hz}$ 이상의 진동수에서 발생되고 있어서 1 차 고유진동 수 보다는 $4.2 \mathrm{~Hz}$ 이상의 문루 고유진동수에서 공 진현상이 발생되는 등의 영향을 미칠 것으로 예상 되며, 추후 해당 진동 모드의 정밀 분석을 통해 구 조 영향성을 분석해 볼 필요가 있다.

또한 상호 대응하는 두 위치에 대한 충격가진 실 험결과로부터 두 위치에서 계측한 전달함수의 크기 와 진동수가 서로 일치하는 것을 확인하였다. 이는 흥인지문의 전체 목구조시스템이 선형으로 거동하 여 상반성이 성립됨을 의미한다.

따라서 우리나라의 전통목조건물의 접합부와 같 은 구조 형식에서도 미소변형 상태에서는 선형성이 유지됨을 알 수 있다. 이러한 성질을 이용하여 향후 현대 건축물에서와 같이 단순화된 선형모델을 작성 하여 수학적 모델을 수립할 수 있을 것으로 판단된 다. 또한 선형성을 바탕으로 센서의 설치 개소 및 충격가진 개소 등도 줄일 수 있을 것이다.

이 논문은 문화재의 동특성 파악을 위한 기초 연 구 결과로써 흥인지문의 진동 특성 분석에 의해 상 반성 등의 선형성을 확인하였다.

전통 목구조의 해석기법 연구는 많이 수행되고 있 다. 그러나 모델의 구현 및 검증이 힘든 접합부는 앞 으로도 많은 연구가 필요한 상황이다. 특히 향후에는 접합부 등의 복잡한 부위를 단순 모형화 할 때 필요 한 물성치의 유추를 위한 연구 및 주기적인 동특성 자료 수집에 따른 구조성능의 변화 파악 등의 연구가 지속적으로 진행 되어야 할 것이다. 이를 위해서는 전통 목구조의 단순 해석기법 연구와 시스템 식별 (system identification)을 통한 해석 모델 개선(model updating) 기법의 적용에 대한 연구가 필요하다.

또한 실험방법에 따른 최적의 측정위치 및 가진 위치 등의 개선을 위한 연구 및 비틀림 모드에 대 한 분석이 향후에 개선되어야 할 것이다.

\section{후 기}

이 연구는 문화재청 국립문화재연구소의 지원을 받아 2009년도 문화재보존기술개발연구(R\&D)사업 의 일환으로 이루어졌으며, 이에 감사드립니다.

\section{참 고 문 헌}

(1) Cultural Heritage Administration of Korea, http://www.cha.go.kr

(2) Konon, W. and Schuring, J. R., 1985, "Vibration Criteria for Historic Buildings," Journal of Construction Engineering and Management, ASCE, Vol. 111, No. 3, pp. 208 215.

(3) Yoon, C. S., Yun, Y. G. and Kang, S. H., 2004, "A Study on the Structural Modeling and Analysis for Gukrak-Pavilion of Bongjung-temple," Journal of The Architectural Institute of Korea: Structure \& Construction, Vol. 20, No. 9, pp. 13 20.

(4) National Research Institute of Cultural Heritage, 2005, "A Study on Assessments of Structural Capacity for Wooden Cultural Heritage," pp. 121 124.

(5) Heylen, W., Lammens, S. and Sas, P., 1997, "Modal Analysis Theory and Testing," Katholike Universiteit Leuven, Belgium, Part A.

(6) Kang, H. G., Jun, D. H. and Park, S. S., 1999, "Estimation of Natural Period by Microtremer Measurement in Shearwall Apartments," Proceedings of the Earthquake Engineering Society of Korea Autumn Conference, pp. 375 382.

(7) Døssing, O., "Structural Testing," 1988, Brüel\& Kjær, Denmark, Part I.

(8) Ahn, S. J. and Jeong, W. B., 2003, "FRF Distortion Caused by Exponential Window Function on Impact Hammer Testing and Its Solution," Transactions of the Korean Society for Noise and 
Vibration Engineering, Vol. 13, No. 5, pp.334 340.

(9) Randall, R. B., 1987, "Frequency Analysis", Brüel\& Kjær, Denmark, chap. 7.

(10) Inman, D. J., 1994, "Engineering Vibration", Prentice-Hall, USA, chap. 7.

(11) Park, J. C., Yu, S. D., Shin, D. S., Lee, J. H. and Sul, J. M., 1999, "Propagation Characteristics of Road Vibration Generated fromm Vehicles," Transactions of the Korean Society for Noise and Vibration Engineering, Vol. 9, No. 1, pp. 25 32.
(12) Huh, Y., Yi, S. S., Kim, H. C., Shin, H. C. and Yi, I. S., 1996, "A Comparison between Measurement Values and Prediction Values for the Decision of Applicability of Vibration Prediction Equations," Proceedings of the KSNVE Annual Spring Conference, pp. 80 85.

(13) Lee, J. W., Kim, D. S. and Chang, S. I., 2001, "Study for the Prediction of Ground-borne Vibration Induced by Subway," Proceedings of the KSNVE Annual Autumn Conference, pp. 1287 1292. 